\title{
Computer Troubleshooting Expert System Damage Certainty Factor Method Using Web Based
}

\author{
Fitri Mijaswari ${ }^{1}$, Sulindawaty ${ }^{2}$ \\ ${ }^{1.2}$ Informatics Engineering Program, STMIK Pelita Nusantara, Jl. St. Iskandar Muda No. 1 \\ Medan, Indonesia 20154 \\ E-mail:fitri.mijaswari@gmail.com,Sulindawaty@gmail.com.

\begin{abstract}
The problems are most common in essence PT.Sinar Blessings Prosperity is still much work to be done manually, as is the case particularly in the logistics department of administration calculations using a single computer, use the computer that is still its own random origin are still common will of computer technology, where if there is damage to require a long time to fix his computer. Therefore, in this study using expert system troubleshooting computer malfunction with the methods certanty factor to help PT. Sinar Inti Sejahtera Blessing in detecting damage to the computer, so as to minimize the company's performance, minimize expenditures on computer repair, thus better able to improve the performance of employees in PT.Sinar Inti Sejahtera Blessing.
\end{abstract}

Keywords: Damage to the computer, Expert System, Certainty Factor

\section{Introduction}

When this computer is a powerful tool helping people work. Almost all areas use the computer to complete the work of man. In line with that required a good enough computer knowledge to anticipate the computer damage due to computer malfunction problem is a fairly complex problem. This may be because the number of users who are less knowledgeable in computers, particularly in addressing damage to the computer. The lack of sufficient knowledge in the handling of damage hardware.mengakibatkan most of the general public or an institution can not identify the location of the damage that occurs in computer hardware. So that many institutions yangmengeluarkan considerable cost just to repair the damage done to computer hardware specialist hardware troubleshooting. For that felt the need to build a software that can help solve the problem of damage to computer hardware. Software to be built would have to be able to present a solution that is precise, accurate, reasonable and efficient. Believed denganpembangunan and use the right software, each institution may save time and money that should be spent for purposes that are far more penting.Software in question is a web-based expert system software that adopt the knowledge that comes from an expert in the field of diagnosis and how handling computer hardware damage. With the construction of an expert system troubleshooting hardware damage web-based computer is expected to provide freedom of access anywhere in assisting computer users in addressing the problems that exist in the hardware computer by presenting an accurate solution, so it can reduce the time and cost to resolve the problems of damage to computer hardware. In the study conducted by Munandar et al (2012), entitled "The Use of Certainty Factor with Multiple Rules for Diagnosing Internal Disease" explaining that the search results of expert system indicates if found concordance between symptoms and diseases, the system will calculate the value of $\mathrm{CF}$ combination in accordance with the rules which exists. Highest level of trust will make the final decision,

\section{Theory}

\subsection{Methods Certainty Factor (Factor Certainty)}

According Zulfian Azmi, ST, and Verdi Yasin M. Kom, Kom., M.Kom: 2019: 91) explains that, according to David McAllister Centainty Factor (Certainty Factor) is a method to prove whether a fact that definitely or uncertain shaped metric that is usually used in an expert system.

In expressing degrees of certainty, Certainty Factor to mengansumsikan degree of certainty an expert to the data. Certainty Factor introduced the concept of belief / belief and disbelief / incertitude. This concept was formulated in the following basic formula:

$$
\mathrm{CF}[\mathrm{H}, \mathrm{E}]=\mathrm{MB}[\mathrm{H}, \mathrm{E}]-\mathrm{MD}[\mathrm{H}, \mathrm{E}] \text {. }
$$

Information:

$\mathrm{CF}=$ Certainty Factor (Certainty Factor) in hypothesis $\mathrm{H}$ which is influenced by the fact $\mathrm{E}$.

$\mathrm{MB}=$ Measure of Belief (Confidence level), an increase in the size of the trust hypothesis $\mathrm{H}$ is affected by the fact $\mathrm{E}$. 
$\mathrm{MD}=$ Measure of Disbelief (Level Unbelief), an increase of distrust hypothesis $\mathrm{H}$ is affected by the fact $\mathrm{E}$.

$\mathrm{E}=$ Evidence (events or facts)

certainty Factor to the rules of the single premise (single premise rules)

$\mathrm{CF}[\mathrm{H}, \mathrm{E}] 1=\mathrm{CF}[\mathrm{H}] \mathrm{CF}[\mathrm{E}]$

certainty Factor for a similar rule (Similiary Concluded Rules)

CFcombineCF $[\mathrm{H}, \mathrm{E}] 1.2=\mathrm{CF}[\mathrm{H}, \mathrm{E}] 1+\mathrm{CF}[\mathrm{H}, \mathrm{E}] 2 *(1 \mathrm{CF}[\mathrm{H}, \mathrm{E}] 1)$

$\mathrm{CF}$ combineCF $[\mathrm{H}, \mathrm{E}]$ old $3=\mathrm{CF}[\mathrm{H}, \mathrm{E}]$ old $+\mathrm{CF}[\mathrm{H}, \mathrm{E}] 3 *(1 \mathrm{CF}[\mathrm{H}, \mathrm{E}]$ old $) \ldots . .(2.4)$

The incorporation of trust and uncertainty into a single number that has two functions, namely first certainty factor is used to level the hypothesis in order of importance.

\begin{tabular}{ll}
\multicolumn{2}{c}{$\begin{array}{c}\text { Table 1. } \\
\text { value CF }\end{array}$} \\
\cline { 2 - 3 } uncertainty Term & CF \\
\cline { 2 - 3 } definitely Not (Definitely not) & -1.0 \\
Almost Certainly Not (Almost certainly) & -0.8 \\
Probably Not (Unlikely) & -0.6 \\
maybe Not (probably not) & -0.4 \\
unknow (do not know) & -0.2 to 0.2 \\
maybe (maybe) & 0.4 \\
Probably (Probably correct) & 0.6 \\
Almost Certainly (Almost certainly) & 0.8 \\
definitely (certainly) & 1.0 \\
\hline
\end{tabular}

Source: T. Sutojo, Edy Mulyanto, Vincent Suhartono (2011: 196)

\section{Research Methods}

\subsection{Framework Research}

Research framework in question is a way that the researchers used in research and collect data compared to a standard or predetermined size on Damage diangnosa Computer expert system using the method of Certainty Factor:

\subsection{Stage Data Collection}

The next stage in this research is data collection. This stage is divided into two, namely the study of literature and rugged data collection.

a) Study of literature

The literature study is done in two ways surf the internet and read books to get information on relevant research object is studied in order to obtain the precision step in the implementation of the study. In addition, to gather resource materials to do research like material on a computer malfunction and methods Centainty Factor

b) Data collection Initial data collection is a step to obtain data to be processed in the implementation process. This data is data of diseases and symptoms as well as the rule used in the expert system.

c) Interview

Once the process is started, the research data obtained by two ways, namely: exploration or literature studies and interviews. Interviews were conducted directly to the area concerned about the damage that this computer is a computer IT who understand about the symptoms and disease in a computer malfunction that happened.

d) analysis

In this analysis phase conducted two phases include:

1) Research data

The point of this study is to collect data that is already in the analysis made as submissions in solving problems.

2) Symptoms and Disease

Symptoms and disease in question is data that a computer malfunction symptoms occur that will be processed on the method used.

e) Selection Symptoms

This stage the election of the symptoms and rules that have been defined from the point of research consistent with the results obtained from the interviews that have been the object of research that has been conducted by researchers, based on the data that is found necessary damage symptoms.

f) development System 
Development of this system is carried out starting from system design up to manufacture the system in accordance with the purposes of the object of research conducted in which already applied methods Centainty Factor.

g) Implementation Method Factor Centainty

The next step is to apply the method has been determined that the methods Centainty Factor in memecehakan problems of the troublehosting damage to the computer.

In applying such methods do several steps in accordance with the method to produce a result of damage by the symptoms of damage incurred.

h) testing Systems

In this phase is done is testing the system that has been created, the purpose of system testing is to determine whether the system that has been made is in conformity with the wishes of the use in diagnosing damage to the computer.

\section{Analysis And Design}

\subsection{Analysis}

Analysis is useful to know the needs of the software needs of Expert System built. In this phase, the search and collection of data and knowledge required by Expert System. So in the end analysis of the results obtained in the form of a system whose structure can be defined well and clearly. The purpose of the analysis system in the development of expert systems is to get the various needs of the user and the system, namely regarding the inputs and outputs must be supplied by the user as well as the needs of the system. The process will be input for the overall system design process. The contents of the list of rules based on the sequence or pattern. During the consultation process between the system and the user, the inference mechanism to test the rules one by one until the conditions of the rule is true.

\section{a. Data analysis}

Before the diagnosis of damage to a computer first data obtained the symptoms of damage and the type of damage that exist on the computer, contained in the following table.

Table 2.

Troublehosting Symptoms Information Computer Damage

\begin{tabular}{llc}
\hline No. & symptom & $\begin{array}{l}\text { Symptoms } \\
\text { code }\end{array}$ \\
\hline 1 & Can not be in Charger battery & G01 \\
2 & Adapter indicator light blinks & G02 \\
3 & There is no indicator of incoming power & G03 \\
4 & When turned on there is the POST but paused not directly enter the operating system & G04 \\
5 & Shown monitored message "Hard Error" or "Hard Faillur" & G05 \\
6 & CPU speed is slow / bad sectors & G06 \\
7 & CD / DVD is not detected & G07 \\
8 & CD / DVD can not read / write / only be read & G08 \\
\hline
\end{tabular}

Table 3.

Damage Type Computers

\begin{tabular}{llc}
\hline No. & \multicolumn{1}{c}{ Damage } & Damage Codes \\
\hline 1 & Damage Adapter Charger & K01 \\
2 & damage Notebook & K02 \\
3 & Damage to CD / DVD ROM & K03 \\
4 & Damage Motherboa rd & K04 \\
5 & damage RAM & K05 \\
6 & damage to the LCD & K06 \\
7 & damage Speaker & K07 \\
8 & USB damage & K08 \\
9 & damage Kyboard & K09 \\
10 & damage Touchpad & K10 \\
11 & damage Batteries & K11 \\
12 & Damage Screen Inverter & K12 \\
13 & Starup Damage Problem & K13 \\
\hline
\end{tabular}

\section{b. Certainty Factor Analysis Method}

The analysis of the Expert System built the (rule-based expert systems) which apply the method of Certainty Factor, Certainty Factor method is one method used to calculate the certainty factor in overcoming the difficulties in determining the symptoms Troublehosting Computer Damage. 